\title{
OS DIREITOS HUMANOS DOS "SEM PÁTRIA"
}

\section{HUMAN RIGHTS OF STATELESS PEOPLE}

Julia García Távora Menegazi

Resumo: A presente pesquisa trata-se de um estudo sobre a apatridia e os problemas que a ocasionam. Essa pesquisa tem como objetivo geral pontuar quais são as dificuldades enfrentadas pelos apátridas e como o Direito Internacional e a legislação brasileira estiveram lidando com o assunto ao longo dos anos. O trabalho introduz o conceito de apatridia para designar as pessoas as quais foram privadas do seu direito a nacionalidade por motivos políticos, burocráticos, de gênero ou religião, abordando exemplos em cada tópico, e com um apenso para falar dos casos mais relevantes ocorridos no Brasil, como o Caso Brasileirinhos, causado devido à Emenda Constitucional 54/2007, e o caso da apátrida Maha Mamo. O projeto também difere os apátridas, refugiados e deslocados internos, além de apresentar as convenções que regulam cada uma dessas categorias. É colocada em discussão também como seria possível evitar a configuração da situação de apatridia para muitas pessoas e a falha do critério ius sanguini na atribuição da nacionalidade. Desse modo, o objetivo é, primeiramente, (i) reconhecer a apatridia como um problema mundial que abrange diversas categorias (ii) observar os critérios que podem vir a gerar a apatridia (iii) verificar quais são as políticas públicas que o Brasil possui nesse quesito.

Palavras-chave: Direitos Humanos. Apatridia. Direito Internacional. Proteção Internacional. 
Abstract: The present article is a study on statelessness and the problems that cause it. This research has as general objective to point out the difficulties faced by stateless persons and how international law and Brazilian law have dealt with the subject over the years. The work introduces the concept of statelessness to designate persons who have been deprived of their nationality rights for political, bureaucratic, degenerate or religious reasons, addressing examples in each topic, and an appendix to speak of the most relevant cases in Brazil, such as Caso Brasileirinhos, caused due to Constitutional Amendment 54/07, and the case of the stateless Maha Mamo. The project also differentiates stateless persons, refugees and internally displaced persons, as well as presenting the conventions which regulate each of these categories. It is also discussed how it would be possible to avoid the configuration of statelessness for many people and the failure of the ius sanguini criterion in the attribution of nationality. Thus, the objective is, firstly, to (i) recognize statelessness as a global problem that encompasses several categories; (ii) observe the criteria that may lead to statelessness; (iii) to check what public policies Brazil has in this question.

Key words: Human Rights. Statelessness. International Law. International Protection.

\title{
1 INTRODUÇÃO
}

\begin{abstract}
"Ser apátrida significa ter uma vida sem acesso à educação e serviços de saúde, e mesmo sem ter um trabalho legalmente reconhecido. É uma vida sem poder transitar livremente, sem perspectivas ou esperança. (ACNUR..., 2014).
\end{abstract}

Ser uma apátrida é muito mais doloroso quando você sabe que sua capacidade é muito maior do que aquilo que te permitem fazer. Você não sabe seu potencial se não te dão o direito de existir (MAHA..., 2016)."

O direito à nacionalidade é considerado pela Organização das Nações Unidas (ONU) como indelegável e de extrema importância. O fenômeno da apatridia retira esse direito dos indivíduos e também outros direitos fundamentais básicos, dentre eles saúde e educação.

O apátrida foi definido por Lisowski como "a inexistência do vínculo jurídico de nacionalidade, ou seja, a ausência de conexão formal entre 
uma pessoa e um Estado qualquer" (LISOWSKI, 2012. p. 109-134), e, atualmente, há 12 milhões de pessoas no mundo em situação de apatridia.

De acordo com a Centro de Informação das Nações Unidas Rio de Janeiro (UNICRio), a dificuldade daqueles que não são reconhecidos como cidadãos de um país é não poderem, com frequência, matricularse na escola, trabalhar legalmente, possuir imóveis, casar-se ou viajar. Podem ter dificuldade em ser hospitalizados e não conseguir abrir uma conta bancária ou receber uma pensão. Se são vítimas de roubo ou de estupro, podem ver-se impossibilitados de apresentar queixa, porque, aos olhos da lei, não existem. Até seus nomes podem não ser reconhecidos. (OS EXCLUÍDOS..., 2007).

Aqueles que não se encaixam em nenhuma categoria definida pelo Estado no qual vivem, os que nunca tiveram nacionalidade ou a perderam devido a efeitos referentes a leis mal concebidas, de sistema de registros falhos, omissões administrativas ou incompatibilidade de sistemas jurídicos de diferentes países são os considerados apátridas.

O UNIC Rio ainda lembra: "Uma minoria importante de apátridas é vítima de uma forma mais perniciosa de privação de nacionalidade: a exclusão de grupos inteiros de pessoas ligada à discriminação política, religiosa ou étnica" (OS EXCLUÍDOS..., 2007).

O direito à nacionalidade é justamente garantido na Declaração Universal dos Direitos Humanos. O Artigo 15 da Declaração coloca que:

"1.Todo o indivíduo tem direito a ter uma nacionalidade.

2.Ninguém pode ser arbitrariamente privado da sua nacionalidade nem do direito de mudar de nacionalidade" (ONU, 2009, p. 9).

Logo, a negação do direito à nacionalidade viola o dispositivo que dispõe sobre os direitos humanos, consequentemente violando os direitos humanos.

A apatridia, o refúgio e o deslocamento interno não são a mesma coisa e nem todo refugiado é apátrida. O deslocado interno, de acordo com os Princípios Orientadores relativos aos Deslocados Internos, fornecido pelo Alto Comissariado das Nações Unidas para Refugiados (ACNUR), é definido como

"pessoas ou grupo de pessoas, forçadas ou obrigadas a fugir ou a abandonar as suas casas ou locais de residência habitual, em especial como consequência de conflitos armados, situações de violência generalizada, violações dos direitos humanos ou calamidades humanas ou naturais, 
ou com vista a evitar os seus efeitos, e que não tenham atravessado uma fronteira internacional reconhecida de um Estado. (PRINCÍPIOS..., [1998], p. [1]).

Sendo assim, o deslocado interno possui uma nacionalidade e não deve ter saído do País, e sim, de suas casas ou cidade. O primeiro tratado internacional a tratar do assunto foi a Convenção da União Africana para a Proteção e a Assistência de Deslocados Internos na África, o qual entrou em vigor em dezembro de 2012.

O conceito de refugiado foi definido na Convenção sobre o Estatuto dos Refugiados de 1951, um dos primeiros tratados internacionais de Direitos Humanos, e qualquer pessoa que se encontre fora do país de sua nacionalidade e não possa ou queira usufruir da proteção desse país por temores referentes à raça, religião, opinião política, grupo social ou nacionalidade (CONVENÇÃO..., 1951). Existem outros dispositivos legais os quais protegem os refugiados, como a Declaração de Cartagena (1984), que, inclusive, adotou uma definição de refugiado abrangendo temores por conflitos armados (DECLARAÇÃO..., 1984).

Já o significado de "apátrida" é definido no Art. $1^{\circ}$ da Convenção sobre o Estatuto dos Apátridas, de 1954, "como toda a pessoa que não seja considerada por qualquer Estado, segundo a sua legislação, como seu nacional" (CONVENÇÃO..., 1954, p. 1). O apátrida, outrossim, será aquele que perdeu a sua nacionalidade ou nunca a possuiu e implica um status de invisibilidade frente aos corpos jurídicos.

A distinção entre a apatridia e o refúgio é que o apátrida é aquele que nunca teve uma nacionalidade atribuída ou perdeu a sua nacionalidade devido a algum problema político, e o refugiado é aquele que se deslocou de seu país de origem, buscando asilo em outro local, bem como proteção jurídica, mas não perdeu seu status de nacional.

A questão dos apátridas começou a surgir no período pós Grandes Guerras Mundiais, quando a eficácia da concepção de nacionalidade e estado iniciaram suas falhas. Os deslocamentos humanos maciços trouxeram problemas em relação a estrangeiros em territórios alheios e a legalização desse processo, desde o poder de permanecer até a ter direitos fundamentais dentro desse Estado.

No fim da Segunda Guerra Mundial, a Alemanha nazista utilizou-se de políticas públicas discriminatórias e xenofóbicas para revogar a nacionalidade dos judeus. 
Anos após as Grandes Guerras, surgiu a Convenção Relativa aos Apátridas, em 1954, referindo-se à situação das pessoas no pós-guerra.

Essa convenção, além de definir o apátrida como "toda pessoa que não seja considerada nacional por nenhum Estado, conforme sua legislação", também considera que os indivíduos não considerados nacionais por nenhum país devem ter seus direitos garantidos pelo Estado no qual residem, bem como a emissão de documentos e facilitação para que Ihes seja concedida a nacionalidade. Entretanto, devido aos conflitos armados e ao cenário no qual o mundo se encontrava, essa convenção foi se aperfeiçoando.

Em 1961, ocorreu a Convenção de Prevenção da Formação de Apátridas, que trata da prevenção da formação de apátridas e compromete os Estados signatários a concederem a nacionalidade para pessoas que nasceram em seu território ou aos filhos de nacionais que perderam a nacionalidade.

A instabilidade política pode gerar conflitos de nacionalidade também, como ocorreu após a dissolução da URSS. Nesse momento, começaram a surgir conflitos étnico-políticos nos países do leste europeu, como a Guerra da Bósnia (1992-1995), Guerra de Independência Eslovena (1991) Guerra de Independência da Croácia (1991-1995), Guerra Civil lugoslava (1991 - 2001), Guerra Croata-Bosníaca (1992-1994), Guerra do Kosovo (1998-1999) e o Conflito na Macedônia (2001).

O caso de RailyaAbulkhanova é um exemplo. "Quando conto que sou apátrida, percebo surpresa, ignorância e desconfiança. É uma reação parecida com aquela de quando alguém revelava que era soropositivo, quando a aids foi descoberta. Há uma total indiferença das pessoas, e isso mata você aos poucos. Você está sempre constrangido" (VIEIRA; GARATTONI, 2014).

Railya Abulkhanova estudava na Rússia quando houve a ruptura da União Soviética, entretanto era nativa do Cazaquistão. Ela trocou seu registro de moradia no Cazaquistão quando estabeleceu sua moradia temporária na Rússia, conforme as leis soviéticas regulavam. Entretanto, com o fim da União das Repúblicas Socialistas Soviéticas, os documentos emitidos na época perderam a validade e as novas repúblicas independentes decidiram que somente aqueles que possuíam residência fixa no país teriam direito à nacionalidade. Sendo assim, Railya perdeu seu direito à nacionalidade e até hoje seu status não foi modificado. Ela ficou noiva mas, no entanto, não pôde se casar e hoje vive no Uzbequistão trabalhando como tradutora. 
Conflitos apátridas podem ser vistos também no cinema, como no filme "O Terminal" (2004), estrelado por Tom Hanks e baseado na história de Merhan Nasseri, iraniano expulso de seu país por participar de manifestações contra o governo. Merhan passou 18 anos morando no Aeroporto Charles de Gaulle em Paris, sendo auxiliado pelos funcionários do local para comer e lavar suas roupas.

\section{A RELAÇÃO DA APATRIDIA E O CRITÉRIO IUS SANGUINI}

O ius sanguini é um critério de nacionalidade que auxilia no surgimento de apátridas em sua expansão. A nacionalidade pode ser atribuída a um indivíduo pelos critérios ius soli ou ius sanguini, sendo definidos pela norma do próprio país (no caso do Brasil, se encontra no Art. 12 da Constituição Federal).

O critério ius soli é atribuído aos que nascem no território e tende a ser utilizado em países que foram colonizados, como, por exemplo. Brasil e Estados Unidos. Já o critério ius sanguini é o reconhecimento da nacionalidade de acordo com a ascendência do indivíduo, ou seja, a nacionalidade passada por gerações. O problema surge quando um casal oriundo de um país ius soli tem um filho em um país com critério ius sanguini, caso o país não tenha uma norma prevendo esse tipo de acontecimento.

A condição de apátrida, relacionada ao princípio ius sanguini para a aquisição da nacionalidade, também está ligada ao gênero em alguns países do Norte Africano, Ásia e Oriente Médio. A história de Zeinab Shehayib é somente uma dentre tantos casos existentes no planeta. Filha de pai egípcio e mãe libanesa, Zeinab não pôde receber a nacionalidade de sua mãe, devido às leis do Líbano não permitirem o repasse da nacionalidade de mulheres a seus descendentes. Como consequência, nunca pôde se casar.

Atualmente, aproximadamente vinte e sete países têm a restrição de gênero no registro de nascimento: as mães não têm direito de transmitir a nacionalidade aos seus filhos. Sendo assim, caso uma mulher tenha filhos sem registro do pai, eles serão apátridas e os filhos de um homem apátrida serão, consequentemente, apátridas e, em alguns países, não são previstas possibilidades legais para os filhos terem outra condição. 


\section{A PROBLEMATIZAÇÃO DA APATRIDIA NO MUNDO: CASO ROHINGYA}

"A migração dos Rohingyas nunca para. Esta comunidade muçulmana é apátrida, sem terra nem direitos. Em Myanmar, que não os reconhece como cidadãos, eles são ameaçados, expulsos das suas casas e vítimas de estupro. Os integrantes da onda mais recente de refugiados apresentam ferimentos de bala, desnutrição e queimaduras" (PALOMO, 2017).

O caso de apatridia mais preocupante atualmente no mundo é sobre o povo Rohingya, uma comunidade de Myanmar que se encontra fugindo por mais de 50 anos. A coordenadora de emergência do MSF, Maria Símon, estima que ainda restem 150.000 deles em Myanmar, 200.000 no Paquistão, 200.000 na Arábia Saudita, 100.000 na Malásia, Indonésia e Tailândia.

\section{ESTUPRO: VIOLÊNCIA E FERRAMENTA DE TERROR EM ROHINGYA}

Em Daca, capital de Bangladesh, além da perda de direitos básicos, há diversos relatos de tráfico infantil para trabalhos sexuais, fora os casos de estupros que ocorrem pelos próprios militares. Um relatório divulgado pela ONG Human Rights Watch acusou as forças armadas birmanesas de promoverem estupros coletivos em série com mulheres e crianças em Mianmar.

Os militares atacam aldeias rohingyas e chamavam de "limpeza étnica", realizada em uma nação predominantemente budista e o estupro tem sido uma ferramenta de terror utilizada na destruição dos rohingyas.

A história de $\mathrm{M}$ e $\mathrm{R}$ (cujos nomes não foram divulgados para preservar a identidade da vítima), são somente exemplos dentre tantos relatos brutais de violência. M. estava com seu irmão e grávida de oito meses, depois de sua família ter fugido e ela não querer deixar o irmão ferido para trás. Quando os soldados finalmente invadiram sua casa, eles a agrediram e estupraram, enquanto davam chutes e socos em sua barriga. Sua bebê nasceu morta. Ela e o marido foram para Bangladesh logo após o episódio. "Eles nos humilharam, destruíram nossas terras e fazendas, levaram nossas vacas, nossos produtos. Como eu voltaria? Destruíram nossa vizinhança". Contou ela (GELINEAU, 2017).

R. tin6ha apenas 13 anos quando os soldados invadiram sua casa e amarraram seus braços em duas árvores para estuprá-la. Dez homens abusaram sexualmente dela até que desmaiasse. 
Phone Tint, coronel e ministro local da segurança, quando questionado sobre os inúmeros casos de estupro, alegou "essas mulheres alegam que foram estupradas, mas olhem suas aparências. Você acha que elas são atraentes para serem estupradas?" (GELINEAU, 2017).

Em 2017, 370.000 muçulmanos da etnia rohingya fugiram de Myanmar para Bangladesh em duas semanas. A população do país, em geral, não fala sobre o assunto. Quando são questionados, dizem que essa gente não pertence ao país, possuindo o discurso político bastante interiorizado, com medo de dizerem algo a favor do rohingyas e contra o governo.

\section{A APATRIDIA NO BRASIL}

O mais complicado caso de apatridia no Brasil foi um lapso na revisão constitucional, segundo Ricardo Glasenapp (2008), pois a Constituição acabou não prevendo os filhos de brasileiros que nasceram no estrangeiro em países de critério ius sanguini. Esses bebês seriam automaticamente considerados apátridas contra a vontade, pois não havia opção de nacionalidade - esta opção estava sendo furtada. Essa situação foi chamada de "brasileirinhos apátridas".

O caso "Brasileirinhos" foi causado devido à Emenda Constitucional 54/2007. Devido a este dispositivo legal, foi alterado o texto da alínea " $c$ " do Artigo 12 da Constituição Federal, transformando-o em:
"Art. 12. São brasileiros:
I - natos:
c) os nascidos no estrangeiro, de pai brasileiro ou de mãe brasileira, desde que venham a residir na República Fede- rativa do Brasil e optem, em qualquer tempo, pela nacio- nalidade brasileira (BRASIL, 2007).

Desse modo, o Texto Constitucional excluiu a possibilidade do pai e mãe brasileiros registrarem os filhos em repartições estrangeiras e restringia a nacionalidade brasileira somente àqueles que viessem a residir no Brasil, necessariamente.

Houve uma grande mobilização, inclusive há um website que trata do assunto, para que, em 2007, fosse criada a PEC 272.000. A Emenda foi promulgada em 2007, restituindo assim a nacionalidade brasileira nata aos filhos de brasileiros nascidos no exterior entre 1994 e 2007 e modificando o Texto Constitucional, deixando o artigo na mesma forma que fora homologado em 1988. 
O movimento não se dissolveu após a promulgação da Emenda 54. Hoje em dia, há outras pautas relevantes referentes à federalização das comunidades brasileiras no exterior, direção e composição da Divisão das Comunidades do Exterior do Itamaraty por emigrantes, aprovação da Emenda 05.2005 e voto por correspondência no exterior para os emigrantes brasileiros (VOCÊ..., [2007]).

Outro caso de apatridia conhecido no Brasil é o da apátrida Maha Mamo. Maha é filha de sírios; entretanto, o casamento na Síria de duas pessoas com religiões distintas é ilegal. Sendo assim, eles se mudaram para o Líbano e ela nunca conseguiu a nacionalidade por seu pai ser sírio e ter um casamento não reconhecido pelo país, não conseguindo emitir nenhum documento comprobatório. Em 2015, devido à descendência síria, ela conseguiu o status de refugiada e veio para o Brasil. Hoje trabalha para o ACNUR com a Campanha BELONG, que tem como o objetivo acabar com a apatridia em 10 anos.

"Eu quero que todo mundo saiba o inferno que eu vivi e que um dia o presidente do Brasil possa ouvir a minha história e me dar uma nacionalidade brasileira. Quando eu receber minha nacionalidade, eu vou gritar! Eu vou chorar! Eu vou atualizar meu status no Facebook! Eu vou para Disney! Para Paris! Para Itália! Vou viajar o mundo inteiro! E vou gritar o mais alto que conseguir: eu finalmente existo!", diz Maha para ACNUR. (A INCRÍVEL..., 2018).

\section{CONSIDERAÇÕES FINAIS}

O problema é algo global e pode ser encarado por diversas dimensões, atentando-se às causas do êxodo de populações e buscando respostas necessárias e importantes desde a raiz do problema, nas situações de emergências e ao repatriamento.

No Brasil, a apatridia demorou a ser reconhecida como um problema a tentar ser resolvido e até mesmo necessidade de políticas públicas para combatê-lo. Um dos modos de precaver alguns conflitos de apatridia ocorridos no Brasil fez com que fosse instaurado o Decreto 8.501, o qual promulgou a Convenção para a Redução dos Casos de Apatridia. A Convenção foi firmada em 30 de agosto de 1961 e somente aceita no Brasil em 18 de agosto de 2015 (BRASIL, 2015). Foram necessários 54 anos para o país aceitar que a apatridia é uma violação de direitos que afeta o mundo todo. 
Criar leis e convenções que evitem a configuração da situação de apatridia para muitas pessoas, como no Brasil, é um grande passo para que a causa seja resolvida, além de assegurar que o direito daqueles que tiveram o direito à nacionalidade tomado de alguma forma sejam resguardados e os apátridas vivam com dignidade até finalmente serem acoIhidos por algum Estado.

\section{REFERÊNCIAS}

ACNUR lança hoje campanha global pelo fim da apatridia até 2024: O Alto Comissariado das Nações Unidas para Refugiados... Agência da ONU para refugiados, Genebra, 2014. Disponível em: <http://www.acnur.org/ portugues/2014/11/04/acnur-lanca-hoje-campanha-global-pelo-fim-da -apatridia-ate-2024/>. Acesso em: 08 nov. 2018.

A INCRÍVEL história da imigrante que viveu 26 anos sem existir oficialmente. Congresso em Foco, [S.I.], 22 jun. 2018. Direitos Humanos. Disponível em: <https://congressoemfoco.uol.com.br/especial/noticias/a-incrivel-historia-da-imigrante-que-viveu-26-anos-sem-existir-oficialmente/>. Acesso em: 08 nov. 2018.

BRASIL. Constituição (1988). Constituição da República Federativa do Brasil. Brasília: Senado, 1988.

BRASIL. Decreto $\mathbf{n}^{\circ} \mathbf{8 . 5 0 1}$, de 18 de agosto de 2015. Promulga a Convenção para a Redução dos Casos de Apatridia, firmada em Nova lorque, em 30 de agosto de 1961. Disponível em: <http://www.planalto.gov.br/ ccivil_03/_ato2015-2018/2015/decreto/d8501.htm>. Acesso em: 09 nov. 2018.

BRASIL. Emenda Constitucional $\mathbf{n}^{\circ}$ 54, de 2007. Dá nova redação à alínea "c" do inciso I do art. 12 da Constituição... Disponível em: <http://www2.camara.leg.br/legin/fed/emecon/2007/emendaconstitucional-54-20-setembro2007-559896-publicacaooriginal-82340-pl.html>. Acesso em: 09 nov. 2018.

CONVENÇÃO relativa ao estatuto dos refugiados. [S.I.: s.n.], 1951. Disponível em: $\quad$ https://www.acnur.org/fileadmin/Documentos/portugues/BDL/Convencao_relativa_ao_Estatuto_dos_Refugiados.pdf >. Acesso em: 09 nov. 2018. 
CONVENÇÃO sobre o estatuto dos apátridas. Nova lorque: [s.n.], 1954. Disponível em: <https://www.acnur.org/fileadmin/Documentos/portugues/BDL/Convencao_sobre_o_Estatuto_dos_Apatridas_de_1954.pdf >. Acesso em: 09 nov. 2018.

DECLARAÇÃO de Cartagena. In: COLÓQUIO SOBRE PROTEÇÃO INTERNACIONAL DOS REFUGIADOS NA AMÉRICA CENTRAL, MÉXICO E PANAMÁ, 1984, Cartagena. Problemas Jurídicos e Humanitários. Cartagena: [s.n.], 1984. Disponível em: <https://www.acnur.org/fileadmin/Documentos/ portugues/BD_Legal/Instrumentos_Internacionais/Declaracao_de_Cartagena.pdf > . Acesso em: 09 nov. 2018.

GELINEAU, Kristen. 'Quando eu terei paz?': mulheres rohingyas relatam estupros em Mianmar. O Globo, [S.I.], 11 dez. 2017. O Globo Mundo. Disponível em: <https://oglobo.globo.com/mundo/quando-eu-terei-paz -mulheres-rohingyas-relatam-estupros-em-mianmar-22176055>. Acesso em: 09 nov. 2017.

GLASENAPP, Ricardo Bernd. O direito de nacionalidade e a EC $n^{\circ}$ 54: a reparação de um erro. Revista Brasileira de Direito Constitucional, [S.I.], n. 11, p. 155-169, jan./jun. 2008. Disponível em: <http://www.esdc.com. br/RBDC/RBDC-11/RBDC-11-155-Ricardo_Glasenapp.pdf >. Acesso em: 09 nov. 2018.

LISOWSKI, Telma. A apatridia e o "direito a ter direitos": um estudo sobre o histórico e o Estatuto Jurídico dos apátridas. Revista jurídica da Procuradoria Geral do Estado do Paraná, Curitiba, n. 3, p 109-134, 2012.

MAHA Mamo, refugiada apátrida no Brasil, fala sobre os desafios de uma vida sem nacionalidade. Agência da ONU para refugiados, São Paulo, 15 dez. 2016. Disponível em: <http://www.acnur.org/portugues/2016/12/15/ maha-mamo-refugiada-apatrida-no-brasil-fala-sobre-os-desafios-de-uma-vida-sem-nacionalidade/>. Acesso em: 08 nov. 2018.

ONU. Declaração Universal dos Direitos Humanos. [S.I.: s.n.], 2009. Disponível em: <https://nacoesunidas.org/wp-content/uploads/2018/10/ DUDH.pdf>. Acesso em: 08 nov. 2018. 
OS EXCLUÍDOS: o mundo desconhecido dos apátridas. Centro de Informação das Nações Unidas Rio de Janeiro, Rio de Janeiro, 26 abr. 2007. Disponível em: <http://unicrio.org.br/os-excluidos-o-mundo-desconhecido-dos-apatridas/>. Acesso em: 08 nov. 2018.

PALOMO, Alberto G. Povo rohingya: o êxodo perpétuo dos apátridas. El País, Madri, 18 dez. 2018. Disponível em: < https://brasil.elpais.com/ brasil/2017/12/13/internacional/1513167960_768282.html>. Acesso em: 09 nov. 2018.

PRINCÍPIOS orientadores relativos aos deslocados internos. [1998]. Disponível em: <https://www.acnur.org/fileadmin/Documentos/portugues/ BD_Legal/Documentos_da_ONU/Principios_orientadores_relativos_aos_ deslocados_internos_1998.pdf?view=1 >. Acesso em: 09 nov. 2018.

VIEIRA, Vanessa; GARATTONI, Bruno. Apátridas: As pessoas de lugar nenhum. Superinteressante, [S.I.], 29 set. 2014. História. Disponível em: $<$ https://super.abril.com.br/historia/apatridas-as-pessoas-de-lugar-nenhum/>. Acesso em: 08 nov. 2018.

VOCÊ está no site internacional dos brasileirinhos apátridas.... [2007?]. Disponível em: <http://www.brasileirinhosapatridas.org>Acesso em: 17 mar. 2018. 